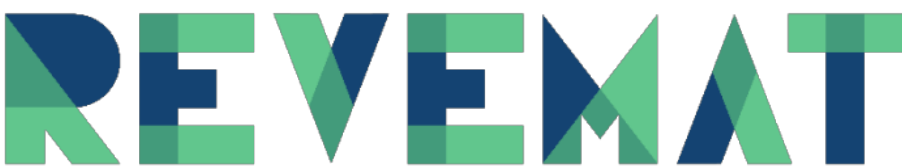

REVISTA ELETRÔNICA DE EDUCAÇÃO MATEMÁTICA

\title{
UMA FORMAÇÃO CONTINUADA, POR MEIO DE ENGENHARIA DIDÁTICA, DE PROFESSORAS POLIVALENTES COM O FOCO EM CONHECIMENTOS E PRÁTICAS PEDAGÓGICAS REFERENTES AO CONCEITO DE NÚMERO NATURAL \\ A continuous training, through didactic engineering, of polyvalent teachers with a focus on knowledge and pedagogical practices related to the concept of natural number
}

Emerson Bastos LOMASSO

Universidade do Estado de Minas Gerais - UEMG, Barbacena/MG - Brasil emerson.lomasso@uemg.br https://orcid.org/0000-0002-2947-722X

A lista completa com informações dos autores está no final do artigo

\begin{abstract}
RESUMO
Este artigo é um recorte de uma tese de doutorado cujo objetivo foi investigar, por meio de uma formação continuada de professoras polivalentes que ensinam matemática, seus conhecimentos sobre o conceito de número natural e suas práticas pedagógicas para ensinar tal conteúdo. A orientação teórica para estabelecer o conceito de número natural nessa formação foi pautada na teoria Piagetiana, tendo como foco o estudo da complementaridade dos aspectos cardinal e ordinal do número natural. Tomou-se como metodologia a Engenharia Didática apresentada por Artigue, na concepção de $2^{a}$ geração de Perrin-Glorian. Os sujeitos da pesquisa foram 8 professoras dos anos iniciais do ensino fundamental de uma escola pública de Belo Horizonte/MG. As situações-problema da sequência didática, uma das componentes da metodologia, foram elaboradas a partir das experiências de Piaget e Szeminska e tomaram por referência elementos da Teoria das Situações Didáticas de Brousseau. A Engenharia Didática se desenvolveu em fases: a análise do conhecimento matemático e das práticas pedagógicas das professoras; a delimitação das variáveis para a elaboração da sequência didática; a experimentação em sala de aula da sequência; o confronto entre a análises a priori e a posteriori. Ficou evidenciado que materiais pedagógicos elaborados com respaldo teórico e focando os aspectos cardinal e ordinal do número natural, propiciam melhor compreensão para os alunos e ampliam o conhecimento dos docentes para sua prática. Acrescenta-se, como resultado, que a metodologia da Engenharia Didática favoreceu a análise dos dados e se configurou como uma metodologia adequada para a formação continuada de professores polivalentes.
\end{abstract}

Palavras-chave: Número natural, Aspectos cardinal e ordinal, Professor polivalente, Engenharia didática

\section{ABSTRACT}

This article is a clipping of a doctoral thesis whose objective was to investigate, through a continuous training of multipurpose teachers who teach mathematics, their knowledge about the concept of natural number and their pedagogical practices to teach such content. The theoretical orientation to establish the concept of natural number in this formation was based on the Piagetian theory, focusing on the study of the complementarity of the cardinal and ordinal aspects of the natural number. The methodology was the Didactic Engineering presented by Artigue, in the 2nd generation conception of Perrin-Glorian. The research subjects were 8 teachers from the initial years of elementary school of a public school in Belo Horizonte/MG. The problem situations of the didactic sequence, one of the components of the methodology, were elaborated from the experiences of Piaget and Szeminska and took as reference elements of Brousseau's Didactic Situations Theory. Didactic Engineering developed in phases: the analysis of mathematical knowledge and pedagogical practices of teachers; the delimitation of the variables for the elaboration of the didactic sequence; classroom experimentation of the sequence; the confrontation between a priori and a posteriori analyses. It was evidenced that pedagogical materials elaborated with theoretical support and focusing on the cardinal and ordinal aspects of the natural number, provide better understanding for students and expand the knowledge of teachers for their practice. It is added, as 
a result, that the didactic engineering methodology favored data analysis and was configured as an appropriate methodology for the continued training of multipurpose teachers.

Keywords: Natural number, Cardinal and ordinal numbers aspects, Multipurpose teacher, Didactic engineering

\section{INTRODUÇÃO}

Definir número natural, assim como conceituar esse objeto matemático considerando a maneira como se processa essa conceitualização pela criança, requer algo além de saber recitar uma ordem numérica. O fato de a criança contar verbalmente a sequência numérica não implica que ela domine o conceito de número.

Estudos sobre como a criança concebe e conceitua número natural vem sendo temática para pesquisas por serem, dentre outros, questões de suma relevância no que tange a conhecer o início do processo de aprendizagem em matemática. Falar em aprendizagem remete a elencar também o ensino, e esse, em se tratando da matemática, apresenta distintos enfoques relacionados às crenças e concepções do professor. Aprofundar no que a criança precisa saber sobre número natural e como leva-la a esse conhecimento, tendo como foco os professores polivalentes que ensinam matemática (suas práticas metodológicas, como conceituam e concebem o número) é a temática que norteia esse artigo, recorte de uma tese de doutorado.

Para tanto considerou-se pertinente investigar, junto a professores polivalentes que ensinam matemática em uma escola pública municipal da cidade de Belo Horizonte/MG, seus conhecimentos sobre número natural e suas práticas pedagógicas no ensino desse conceito matemático, por meio da Engenharia Didática de $2^{\mathrm{a}}$ Geração, definindo-a ou não, como metodologia eficaz.

O ensino do número tem sido alvo de muitas discussões no campo da educação matemática, dado o quão é relevante esse conteúdo. Segundo Belline, Burgo e Nogueira (2007), antes do Movimento da Matemática Moderna era predominante ensinar número a partir da habilidade de contagem com a sequência de palavras/número e, dando ênfase à leitura e à escrita dos numerais.

Para Panizza (2006, p. 44), "um dos enfoques arraigados à prática docente no ensino do número era a do ensino clássico. Nesse predominava ensinar os números aos poucos, um a um e na ordem em que a série numérica indica”. A escrita convencional dos números é central e com isso escrever linhas inteiras do mesmo número era atividade considerada 
fundamental. Uma das ideias principais é a de que o conhecimento entrava pelos olhos, imitando e copiando.

Diante disso, foi realizado nesta pesquisa, o estudo do desenvolvimento cognitivo relacionado ao número natural segundo a teoria Piagetiana. Jean Piaget (1896 - 1980) desenvolveu, dentre outros, um estudo de como a criança se apropria e constrói o conceito do número natural. Juntamente com Alina Szeminska (1907-1986), Piaget desenvolveu experiências com crianças buscando compreender como elas concebiam e conceituavam o número natural. Esses experimentos são relatados no livro "A gênese do número na criança", que contribuíram para com o desenvolvimento da tese - base deste artigo - sobre desenvolver uma prática pedagógica com professoras polivalentes que ensinam matemática. Essa prática priorizou as características basais para a existência do número natural, segundo Piaget e Szeminska (1975), em especial os aspectos cardinal e ordinal.

Quanto a formação das professoras, sujeitos da pesquisa, o levantamento apontou que essa não acontece de forma satisfatória em se tratando da área de matemática. De acordo com Curi (2004), a concepção que fica sobre os cursos de formação inicial é de que o professor polivalente precisa saber somente ensinar matemática, sem a necessidade de ter conhecimentos sobre seus conceitos. Tal fato ocasiona alguma dificuldade junto à prática do magistério, pois, ainda segundo Curi (2004), há uma complexidade no processo de formação inicial de professores polivalentes e, a esses fatores, soma-se o desafio desses profissionais construírem competências específicas para lecionar diversas áreas do conhecimento.

Quanto às competências relacionadas ao ensino de matemática, em especial ao ensino do número natural, foi possível constatar que estas eram direcionadas, exclusivamente, pela teoria de Jean Piaget. Essa situação também foi observada no exame da realidade pedagógica dos sujeitos de pesquisa, uma vez que desenvolvem suas práticas metodológicas em matemática respaldados pela teoria Piagetiana. Segundo Piaget e Szeminska (1975) um número só é concebível se satisfizer, dentre outras, a propriedade da determinação dos valores cardinal e ordinal. Identificada a dificuldade dos sujeitos de pesquisa em conceituar e conceber o número natural, combinou-se esta à teoria piagetiana, visto que, a maioria dos professores polivalentes que ensinam matemática, quando ensinam número natural, enfatizam a função ordinal em detrimento da cardinal (Carvalho, 2010).

Assim sendo a tese foi norteada tendo como questão de pesquisa, o levantamento das contribuições didáticas nas práticas docentes observadas em uma formação 
continuada com professoras polivalentes, quando os aspectos cardinal e ordinal de números naturais são abordados de forma complementar.

Com base na revisão bibliográfica, suportada pelo referencial teórico e diante do que se pretendia com a pesquisa, ficou constatado que, as características da Engenharia Didática apresentam meios de fortalecer uma formação continuada de docentes. Tal processo foi concebido ao combinar o cotidiano da sala de aula do professor polivalente, quando esse ensina número natural, com um processo de formação continuada, por meio de uma sequência didática de atividades envolvendo situações-problema. A opção por essa metodologia se deu devido ao fato de ela favorecer um estudo experimental baseado em realizações didáticas. Essas são pautadas na observação e análise de sessões de ensino envolvendo a complementaridade de aspectos do número, a qual buscou-se por meio desse trabalho, mostrar ser fundamental no ato de ensinar.

\section{A CONSTRUÇÃo do NÚMERO NATURAL SEGUNDO A TEORIA PIAGETIANA}

Depois de anos estudando o desenvolvimento infantil, Jean Piaget (1896 - 1908) com a ajuda de Alina Szeminska (1907 - 1986) começou a procurar respostas para como a criança organizava seus esquemas em nível de pensamento operatório. Segundo esses autores, a construção do conceito de número pela criança é realizada seguindo uma relação próxima com a conservação numérica (invariância do número), com as operações lógicas de classificação (como classe de inclusão) e a seriação das relações assimétricas (ordenação de grandezas). Piaget e Szeminska (1975) partem do princípio de que o conhecimento, seja ele de ordem científica ou se origine do simples senso comum, supõe um sistema, explícito ou implícito, de princípios de conservação. Diante dessas ideias de conservação, Piaget e Szeminska (1975, p. 23) chegaram ao pensamento aritmético, afirmando que "um conjunto ou uma coleção não são concebíveis a não ser que seu valor total permaneça inalterado, sejam quais forem as mudanças introduzidas nas relações dos elementos". Ainda segundo os autores, para que o número natural exista, ele deve satisfazer a algumas qualidades, ou seja, conservação de quantidades, correspondência termo a termo, determinação do valor cardinal e determinação do princípio ordinal.

Alguns autores e educadores matemáticos ressaltam a importância de se trabalhar os aspectos cardinal e ordinal do número natural de forma dual, ou seja, sem priorizar um 
deles, abordando-os de forma complementar. Para Piaget e Szeminska (1975) isso deve ser feito para que a correspondência seja exata, de modo que cada termo seja contado apenas uma vez, sendo necessário que os diferentes termos estejam ordenados numa série que permita distinguir cada termo de todos os outros. Na percepção deles, esses dois aspectos se mostram tão complementares que a ausência da seriação espontânea vai de par com a ausência de correspondência cardinal espontânea.

A relação entre os aspectos cardinal e ordinal do número natural é classificada por Otte (2003) como relação dual, assim como a noção de complementaridade de Niels Bohrs (1885 - 1962). Ela é utilizada para analisar e explicar o desenvolvimento epistemológico e cognitivo de conceitos matemáticos, em especial as noções de conjuntos e números. Ainda segundo Otte (2003) a complementaridade relacionada à noção de número é concebida segundo os aspectos intensional e extensional desse conceito, que não devem ser vistos apenas como uma dualidade, mas sim como complementares no desenvolvimento do conceito de número.

\section{ELEMENTOS EMPÍRICOS DA PESQUISA}

A pesquisa fundamentou-se em uma proposta metodológica voltada para a formação continuada de professores que ensinam matemática nos anos iniciais do ensino fundamental em uma escola pública municipal de Belo Horizonte/MG, tendo como objeto de estudo a construção do conceito do número natural. Para tanto a Engenharia Didática foi adotada como metodologia de pesquisa. Segundo Artigue (1988, p. 285), "a Engenharia Didática se caracteriza como um esquema experimental baseado nas realizações didáticas em sala de aula, ou seja, na concepção, realização, observação e análise de sequências de ensino". Ainda segundo a autora, a Engenharia Didática perpassa por quatro fases: análises preliminares, concepção e análise a priori das situações didáticas, experimentação e análise a posteriori e validação.

Nessa metodologia, considera-se um conteúdo do sistema de ensino cujo seu aproveitamento é pouco satisfatório. A intenção é, por meio das análises elencadas, propor mudanças capazes de minimizar o contexto insatisfatório que a ocasionou. No caso desse trabalho, refere-se ao ensino do número natural nos anos iniciais do ensino fundamental. Dentre as distintas concepções da Engenharia Didática e segundo o contexto ao qual a mesma será investigada, optou-se pelo tipo que consiste em um trabalho voltado para a 
formação de professores e para a produção de recursos didáticos pedagógicos, ou seja, a de $2^{a}$ Geração.

Aliada a metodologia adotada nesta pesquisa, a Teoria das Situações Didáticas de Brousseau (1986) serviu como apoio teórico para a elaboração da sequência de atividades desenvolvidas com as professoras, sujeitos de pesquisa. Para Artigue (1988), a Teoria das Situações surgiu a partir do questionamento e crítica de uma série de tendências que podem influenciar o ensino da matemática.

Considerado como pai da teoria das situações didáticas, Guy Brousseau buscou compreender como acontecem as relações entre alunos, professores e o saber em sala de aula, propondo situações que foram experimentadas e analisadas cientificamente.

Em suma, o objetivo da Teoria das Situações Didáticas consiste em evidenciar um processo de aprendizagem, tendo como base uma série de situações que se reproduzem, acarretando mudanças de comportamentos dos alunos, sujeitos esses que, na conjuntura desta pesquisa, enquadraram-se as professoras polivalentes.

\section{A METODOLOGIA E OS SUJEITOS DE PESQUISA}

Quanto ao professor, nessa proposta metodológica, ele tem a oportunidade de avaliar e refletir sua própria conduta pedagógica. Assim, a proposta não é dar aos professores, soluções para as questões metodológicas, mas sim, segundo Perrin-Glorian e Mangiante-Orsola (2016), desenvolver pesquisas básicas e estruturas teóricas que permitam estudar os fenômenos didáticos, proporcionando, dessa forma, ferramentas que ajudem os professores a gerenciar os problemas de ensino e aprendizagem.

A escola na qual foi desenvolvida a pesquisa conta com 25 professoras polivalentes, atuando nos dois primeiros ciclos dos anos iniciais do ensino fundamental. Desse total, 15 professoras ensinam matemática. Quanto a participação das mesmas na pesquisa, no primeiro momento da formação participaram 8 docentes e no segundo 5.

Portanto, foi de interesse desse projeto analisar a postura pedagógica do professor polivalente ao ensinar números naturais com amparo dessa metodologia que atravessa um processo constituído por determinados níveis. A cada nível alcançado, o objeto do conhecimento pesquisado atinge um determinado patamar, o que faz com que o professor repense e reavalie seus objetivos e propósitos. 


\section{A METODOLOGIA ENGENHARIA DIDÁTICA E SUAS ETAPAS}

\subsection{Análises Prévias}

Na primeira fase da Engenharia Didática, as análises prévias, é possível refletir sobre a forma como a estrutura do trabalho a ser desenvolvido pelo professor deve acontecer. Essa etapa ocorre a partir de considerações sobre o quadro teórico e conhecimentos didáticos adquiridos sobre o tema. Ainda nessa fase, se desenvolve o estudo da organização matemática, a análise da organização didática do objeto matemático escolhido e a definição das questões da pesquisa.

Segundo Artigue (1996), as análises preliminares realizadas pelo pesquisador devem ser retomadas no decorrer das fases seguintes do trabalho. Ainda para Artigue (1996):

A primeira fase está estruturada à volta da análise do funcionamento do ensino habitual, considerado como o estado de equilíbrio do funcionamento de um sistema, um equilíbrio que, durante muito tempo, foi estável, mas cuja obsolescência começa a fazer-se sentir. $O$ extrato seguinte põe claramente em evidência as escolhas efetuadas a este nível e a forma como estas escolhas estão ligadas à perspectiva sistémica que constitui o fundamento teórico da análise. A investigação aqui documentada situa-se numa perspectiva de engenharia didática clássica: considerase um ponto do sistema didático, cujo funcionamento parece, por razões que podem ser de natureza diversa, pouco satisfatório. Analisa-se esse ponto do funcionamento e os constrangimentos que tendem a fazer dele um ponto de equilíbrio do sistema e depois, jogando com estes constrangimentos, procura-se determinar as condições de existência de um ponto de funcionamento mais satisfatório. (Artigue, 1996, p.199).

\subsection{Análise a priori}

No nível da análise a priori, o professor/pesquisador busca determinar um número de variáveis a serem consideradas no processo. Isso pode ser realizado por meio da construção de hipóteses estabelecidas inicialmente por ele e que serão analisadas e validadas nas próximas fases. Para Brousseau (2004), o cálculo das situações e o estudo de suas variáveis são as bases do estudo a priori, indispensáveis tanto à observação da contingência quanto à produção de dispositivos com características conhecidas, descritas e presumidas, a Engenharia Didática.

\subsection{Experimentação}


A próxima fase da Engenharia Didática, a experimentação, é marcada por colocar em ação toda a situação-problema. Este é o momento clássico da metodologia, pois é onde se coloca em funcionamento todo o instrumento elaborado, sendo que este deve ser corrigido sempre que necessário, ou seja, retornar às análises a priori (ALMOULOUD, 2007).

\subsection{Análise a posteriori e validação}

Essa etapa corresponde ao conjunto de resultados que se obtém diante dos trabalhos desenvolvidos por meio da sequência didática. Formatado a partir das variáveis elencadas na análise a priori, a sequência didática de atividades "contribui para a melhoria dos conhecimentos didáticos que se têm sobre as condições da transmissão do saber em jogo" (Almouloud, 2007, p. 177). Ainda segundo Almouloud (2007), essa fase:

Depende das ferramentas técnicas (material didático, vídeo) ou teóricas (teoria das situações, contrato didático etc.) utilizadas com as quais se coletam os dados que permitirão a construção dos protocolos de pesquisa. Esses protocolos serão analisados profundamente pelo pesquisador e as informações daí resultantes serão confrontadas com a análise a priori realizada. O objetivo é relacionar as observações com os objetivos definidos a priori e estimar a reprodutibilidade e a regularidade dos fenômenos didáticos identificados (Almouloud, 2007, p. 177).

\section{O DESENVOLVIMENTO DA ENGENHARIA DIDÁTICA NA PESQUISA}

\subsection{A análise preliminar na pesquisa}

Considerando as características dessa fase na Engenharia Didática, foi analisado o ensino do número natural nos anos iniciais do ensino fundamental e seus efeitos, partindo das práticas metodológicas usadas pelas professoras. Fez-se ainda um estudo das propostas curriculares para essa etapa de ensino adotado pela Prefeitura Municipal de Belo Horizonte/MG, tomando como referencial o objeto matemático pesquisado. Quanto aos principais problemas relacionados ao ensino e à aprendizagem do número natural, constatou-se que, dentre outras, o que se refere a ensinar os aspectos cardinal e ordinal de forma complementar, predomina entre as professoras, ou seja, pode haver o tratamento de um conceito em detrimento do outro. 
Com intuito de nortear e clarear o entendimento do propósito desse trabalho, foi realizado um levantamento teórico sobre a formação do professor polivalente. Estudos como legislação, características do curso, currículo, dentre outros, foram elencados de forma a posicionar e caracterizar o professor dos anos iniciais do ensino fundamental.

\subsection{A análise a priori na pesquisa}

Com base nos estudos feitos nas análises preliminares, foi elaborado e aplicado um questionário para as professoras, cujas respostas serviram de referencial para 0 levantamento das variáveis de estudo dessa fase da metodologia, as quais resumiram-se em: resgatar a ideia de número natural enfatizando os aspectos cardinal e ordinal e; promover a interação entre as professoras de tal modo que as mesmas externassem suas experiências sobre o ensino do número natural, gerando um confronto de ideias, tais que servissem para elucidar a eficácia ou não de algumas práticas metodológicas desenvolvidas.

De posse dessa investigação, foi elaborada uma sequência didática de atividades do tipo situações-problema. Para essa construção foram priorizadas algumas características, tais como: se as professoras entenderiam facilmente os dados do problema e se os conhecimentos que elas possuíam seriam suficientes para resolver as situações. Diante disso, as atividades contempladas na sequência tiveram como eixo norteador as experiências de Piaget e Szeminska (1975) abordadas no livro A gênese do número na criança. Para que essas atividades alcançassem os objetivos previstos - os quais se resumem em uma nova proposta metodológica para o ensino do número natural nos anos iniciais -, foram escolhidas situações que provocassem mudanças no processo de ensino e aprendizagem. As análises dessas foram realizadas observando-se as questões epistemológicas, cognitivas e didáticas. A primeira, associada às características do saber, buscou nos parâmetros curriculares adotados pela Secretaria Municipal de Educação de Belo Horizonte/MG, significar todos os ciclos em que se ministra o conceito de número natural, seja na fase inicial e/ou ao iniciar as operações adição e multiplicação. Esses momentos foram priorizados tendo em vista o ano em que as professoras lecionavam.

Para a questão cognitiva, o referencial foi o questionário que as professoras responderam. Partindo das respostas, foi possível elencar algumas hipóteses sobre o 
conhecimento que elas tinham a respeito do conceito de número e as práticas adotadas para ministrar esse conteúdo.

A questão didática está associada às características do sistema de ensino em que as professoras estão inseridas. As docentes, como supracitado, lecionam em uma escola pública situada na periferia de Belo Horizonte/MG e convivem com muitas dificuldades, delas e dos alunos, que perpassam o campo didático, pedagógico e cognitivo. Conversas desenvolvidas entre pesquisador e sujeitos de pesquisa, a respeito do processo de ensino e aprendizagem que é desenvolvido em sala de aula, forneceram argumentos que ajudaram no levantamento das variáveis de estudo nessa fase da metodologia.

\subsection{A experimentação na pesquisa}

Adaptando as características dessa fase da Engenharia Didática a proposta da pesquisa, foi ofertada uma formação às oito professoras, abordando experimentos desenvolvidos por Piaget e Szeminska (1975) - particularizando o conceito do número natural - sendo que essa foi dividida em dois momentos. O primeiro deles, foi constituído por duas etapas, tal que na primeira as docentes desenvolveram as atividades da sequência didática entre elas e em seguida, com seus respectivos alunos (as). Ambas as etapas foram observadas pelo pesquisador, cuja intenção do mesmo foi analisar as professoras executarem em suas práticas pedagógicas, o recurso metodológico oferecido por meio da formação.

No segundo momento foi proposta outra formação cujo objetivo foi apresentar a teoria abordada nas experiências desenvolvidas por Piaget e Szeminska (1975) apresentadas anteriormente. Essa fase teve como eixo norteador a Engenharia Didática de $2^{\mathrm{a}}$ geração.

Na didática da matemática há diferentes concepções da Engenharia Didática. Elas se dividem em Engenharia Didática Clássica ou de $1^{\mathrm{a}}$ Geração, Engenharia Didática de $2^{\mathrm{a}}$ Geração, Engenharia Didática do Percurso de Estudo e Pesquisa (PER) e Engenharia Didática de Domínios de Experiência.

Por sua vez, a Engenharia Didática de $2^{a}$ Geração se ramifica em dois tipos, dando origem à proposta da Engenharia Didática de Investigação (IDR) e à de Desenvolvimento (IDD). A primeira analisa os fenômenos didáticos com a intenção de avançar nos resultados da investigação, por meio de experimentações elaboradas em função da questão de 
pesquisa, enquanto a segunda visa a produzir recursos para professores ou para a formação deles.

Desse modo, a segunda ajustou-se aos objetivos da pesquisa, que tratou da formação continuada para professores polivalentes. Nesse sentido, essa investigação buscou produzir recursos para o ensino do número natural para professores polivalentes, além de investigar as situações atuais desses docentes, suas exigências, culturas e crenças sobre o ensino e a aprendizagem do número, seus conhecimentos matemáticos e didáticos necessários para a implementação das situações didáticas com seus alunos.

Essa escolha fundamenta-se em Perrin-Glorian e Mangiante-Orsola (2016), visto que, segundo essas autoras, desenvolver uma Engenharia Didática com professores é um meio de estudar como eles lidam com os conteúdos, identificando suas necessidades e o conhecimento que os mesmos têm da profissão e, diante disso, continuar o estudo da transposição didática. E complementam:

O projeto visa a desenvolver pesquisas básicas e estruturas teóricas que nos permitam estudar fenômenos didáticos e, ao invés de dar aos professores soluções, dar-lhes-á ferramentas que os ajudem a gerenciar os problemas de ensino e aprendizagem que encontram em suas vidas diárias (Perrin-Glorian; MangianteOrsola, 2016, p. 2).

Ao analisar as práticas pedagógicas das professoras polivalentes, quando elas estão ensinando número natural, essa pesquisa buscou compreender como elas conceituam esse objeto matemático. A prática pedagógica sucede à forma como se processa todo entendimento a respeito desse conteúdo. Caracterizando todo esse contexto, buscou-se intervir junto ao mesmo de tal forma que o produto dessa formação pudesse somar ao cotidiano da sala de aula dessas professoras, indo ao encontro dos objetivos da Engenharia de Desenvolvimento e Formação. Ainda segundo Perrin-Glorian e Mangiante-Orsola (2016):

Como esses resultados podem ser traduzidos para um professor que precisa preparar e administrar sua classe, organizar o trabalho de seus alunos para garantir seu aprendizado, por um pesquisador em contato direto com as demandas urgentes dos professores? Um professor precisa integrar esses resultados em seu funcionamento normal e levando em conta os resultados da pesquisa, relacionados a certos aspectos de seu trabalho para a exclusão de outros, o mesmo pode desestabilizar mais do que melhorar a prática, partindo da resistência dos professores quanto aos efeitos as vezes negativos da disseminação da pesquisa na educação. Para que a pesquisa contribua para a melhoria da formação e treinamento de professores, ela deve ter em conta o funcionamento real das classes e as necessidades dos professores (Perrin-Glorian; Mangiante-Orsola, 2016, p. 2).

Dessa forma, foi de suma relevância a compreensão de todo o processo percorrido pelas professoras ao conceituar e ensinar o número natural. Por meio do questionário, 
buscou-se verificar como as docentes lidam com situações típicas de sala de aula, pois, de acordo com as autoras supracitadas, a questão de investigação deve priorizar os anseios delas, como também as necessidades identificadas pelo pesquisador.

\subsection{Análise a posteriori na pesquisa - resultados da formação}

Conceituar e ensinar número natural priorizando de forma dual seus aspectos cardinal e ordinal foi uma das questões mais destacadas, seja pelos estudos teóricos ou diretamente identificados pelo pesquisador diante das respostas de um questionário respondido pelas professoras sujeitos da pesquisa.

Portanto, na elaboração das situações-problema, priorizou-se desenvolver atividades contemplando o conceito de número natural por meio da seriação, ordenação, cardinação e conservação de quantidades. Esperava-se que diante dessa formatação, bem como da ampla coleta de dados, fosse possível contribuir para com o conhecimento das professoras sobre o assunto e, por consequência, dos seus respectivos alunos. Assim avaliam Perrin-Glorian e Mangiante-Orsola (2016):

Na engenharia didática para o desenvolvimento e a formação, procuramos ter acesso simultâneo a um número bastante elevado de turmas e desenvolver um recurso útil para o máximo possível dessas turmas, de tal forma que isso possa melhorar a aprendizagem dos alunos (Perrin-Glorian; Mangiante-Orsola, 2016, p. 4).

Para a primeira das duas variáveis elencadas na análise a priori - resgatar a ideia de número natural enfatizando os aspectos cardinal e ordinal - objetivou-se solidificar o entendimento das professoras sobre esse objeto matemático enfatizando seus aspectos.

No primeiro momento da formação as experiências piagetianas foram apresentadas por meio de uma sequência didática de atividades. Buscou-se contemplar todos os princípios piagetianos que compõem a conceituação genética do número natural. Nessa ocasião não foi discutido com as professoras nada a respeito sobre como resolver as situações, ou seja, nenhuma teoria a respeito foi explanada (Quadro I).

Quadro 1: Situação-problema - Formação

\begin{tabular}{|c|c|}
\hline $\begin{array}{l}\text { Primeira situação-problema } \\
\text { Os cartões em escada } \\
\text { Essa sequência didática visa levar às professoras } \\
\text { atividades que as proporcionem uma releitura das } \\
\text { ideias de conservação de quantidades, da } \\
\text { ordenação e cardinação. Segundo Piaget e } \\
\text { Szeminska (1975), por meio da ordenação de } \\
\text { elementos dispostos em duas fileiras }\end{array}$ & $\begin{array}{l}\text { Segunda situação-problema } \\
\text { Os tapetes e as barreiras } \\
\text { Quando se diz que alguém está em seu vigésimo } \\
\text { ano, isso significa que esse alguém não possui mais } \\
\text { que dezenove anos feitos; desde logo, é mais fácil } \\
\text { para a análise, embora mis difícil para o sujeito, } \\
\text { distinguir em caso semelhante o aspecto ordinal, } \\
\text { que é o do ano em via de escoamento, do aspecto }\end{array}$ \\
\hline
\end{tabular}


correspondentes é possível atribuir um valor cardinal a esses conjuntos. Ainda segundo os mesmos, a criança consegue distinguir as diferentes unidades que vêm uma após a outra, levando em consideração a reunião de cada uma dessas às suas precedentes. Espera-se, com essa atividade, que as professoras a levem aos seus alunos quando trabalharem o conceito de número, abordando os aspectos cardinal e ordinal do mesmo, entre outros. Assim propõem Piaget e Szeminska:

Começa-se por pedir à criança para confeccionar ela própria a série, para que tome consciência do princípio desta ordenação e se lhe faz contar os cartões interrompendo seu número em 10 ou no limite da numeração conhecida sem hesitação. Após isso, perguntase: "Quantos cartões como (A) poder-se-ia fazer com (B), ou

(C) etc", até que o sujeito compreenda que o segundo cartão pose ser decomposto em 2; o $3^{\circ}$ em $3 A$ etc. Uma vez compreendida esta lei, designa-se um cartão qualquer (F por exemplo), com a escada permanecendo inteira, e pergunta-se quantas unidades se poderia fazer com esse cartão. É a solução descoberta pela criança para este terceiro tipo de questão que nos interessa aqui: se o sujeito é capaz de fazer corresponder de saída o valor cardinal 6 desse cartão $F$ à sua posição $\left(6^{\circ}\right)$, é claro que a relação entre a ordenação e a cardinação se acha adquirida (Piaget \& Szeminska, 1975, p. 192).

\section{Objetivos}

- Consolidar o princípio da ordenação de elementos;

- Desenvolver o controle da contagem;

-Desenvolver e estender o significado das expressões "maior que" e "menor que";

- Desenvolver a ideia de cardinal e ordinal.

\section{Atividade}

Há um quadrado de cartão $A$, representando uma unidade, um retângulo $B$, que possui a mesma largura que $A$ e duas vezes sua altura (representando, portanto, duas unidades), um retângulo $\mathrm{C}$ a representar 3 unidades superpostas (mesma largura e 3 vezes a altura) e assim sucessivamente. Tem-se, portanto, $A=1 ; B=2 A ; C$ $=3 \mathrm{~A} ; \mathrm{D}=4 \mathrm{~A} ; \mathrm{E}=5 \mathrm{~A} ; \mathrm{F}=6 \mathrm{~A} ; \mathrm{G}=7 \mathrm{~A} ; \mathrm{H}=8 \mathrm{~A} ; \mathrm{J}=$ $9 \mathrm{~A}$ e $\mathrm{K}=10 \mathrm{~A}$.

a) Construa a sequência da série desses cartões usando o material de apoio.

b) Quantos cartões como A podem ser feitos com $B$, ou $C$, ou $D$ ?

c) Tome aleatoriamente um cartão qualquer. Quantos unidades podem ser feitas com esse cartão? cardinal, que é o dos anos completados, do que no caso em que as duas noções coincidem. Unicamente, como a medida do tempo é especialmente complicada para a criança, procuramos um equivalente espacial da situação (Piaget \& Szeminska, 1975, p. 198).

Com base nessa citação, pode-se depreender o quão é complexa a abordagem dos aspectos cardinal e ordinal do número natural, principalmente em se tratando do $1^{\circ}$ ciclo do ensino fundamental. Por isso, buscou-se, por meio de mais uma das experiências de Piaget e Szeminska (1975), levar às professoras ferramentas capazes de auxiliar na reflexão e adaptação de técnicas para se ministrar o ensino do número natural. Para essa experiência, Piaget e Szeminska propõem:

Seja um escolar que se exercita no salto: ele passa por cima de uma primeira barreira, depois de uma segunda mais alta, uma terceira mais alta ainda, etc., até a sétima. Mas, para tomar impulso e cair sem se ferir, tem necessidade, achando-se com sapatos de ginástica, de pequenos tapetes que se estendem sobre o chão antes e depois de cada barreira, ou seja, 8 tapetes ao todo. Apresenta-se naturalmente ao sujeito um material composto de 7 barreiras graduadas, 8 pequenos tapetes de dimensões constantes e de um boneco que desempenha o papel de ginasta. Desta maneira, se o boneco se acha sobre o $3^{\circ}$ tapete, isso significa que saltou 2 barreiras, e se ultrapassou a $5^{\text {a }}$ barreira significa que tocou em 6 tapetes etc. (Piaget \& Szeminska, 1975, p. 198).

O propósito é de que as professoras identifiquem a ideia de seriação entre o número dos tapetes e o das barreiras, como também a ideia da composição ordinal enquanto determinada por um número dado de tapetes.

\section{Objetivos}

- Consolidar a ideia de seriação e/ou seriar uma coleção;

- Consolidar a ideia de correspondência entre dois conjuntos distintos;

- Desenvolver a ideia de cardinação ou número cardinal, determinado pela posição dos elementos de uma coleção;

- Introduzir e desenvolver a ideia de cardinação e ordenação usando a complementaridade.

\section{Atividade}

Um atleta de corrida com obstáculos passa por cima de uma primeira barreira, depois de uma segunda mais alta e de uma terceira mais alta ainda, consecutivamente, até a sétima. Para tomar impulso e cair sem se ferir, tem necessidade, achando-se com sapatos de ginástica, de pequenos tapetes que 


\begin{tabular}{|l|l|}
\hline $\begin{array}{l}\text { d) Elenque os objetivos de se trabalhar os } \\
\text { conceitos de número cardinal e ordinal dentro } \\
\text { dessa perspectiva lúdica. }\end{array}$ & $\begin{array}{l}\text { se estendem sobre o chão antes e depois de cada } \\
\text { barreira, somando, ao todo, } 8 \text { tapetes. }\end{array}$ \\
& $\begin{array}{l}\text { Perguntas } \\
\text { a) Após haver colocado os 2 primeiros } \\
\text { tapetes antes e depois da primeira barreira, } \\
\text { quantos tapetes é preciso pôr para demais } \\
\text { barreiras? } \\
\text { b) Quantas barreiras foram saltadas e } \\
\text { quantos tapetes foram tocados estando o boneco } \\
\text { sobre o 4 tapete? } \\
\text { c) Retirando-se os 8 tapetes e algumas } \\
\\
\text { barreiras aleatoriamente, quantos tapetes são } \\
\text { necessários para as barreiras restantes? } \\
\text { d) Considerando sua prática pedagógica } \\
\text { usada para ensinar o número natural e seus } \\
\text { aspectos cardinal e ordinal, você usaria algumas } \\
\text { dessas situações problema para somar ou } \\
\text { substituir a sua metodologia? }\end{array}$ \\
\hline
\end{tabular}

Fonte: Elaborado pelo autor.

Como parte da sequência, buscou-se saber das professoras como elas compreendiam os objetivos envolvendo cada uma das experiências desenvolvidas, relacionadas ao número natural. Diante das respostas pôde-se concluir que as docentes visualizaram as propostas apresentadas, mas não as atribuíram como sendo princípios Piagetianos relativos à concepção genética do número natural. Ainda relativamente a essa etapa da formação, por meio da sequência de atividades pôde-se concluir que as professoras utilizam pouco em suas aulas, ao trabalharem com número natural, os materiais manipulativos, tal como foi apresentado.

e) Qual(ais) prática(s) pedagógica(s) você utiliza para abordar as ideias envolvendo número natural contidas nas situações acima?

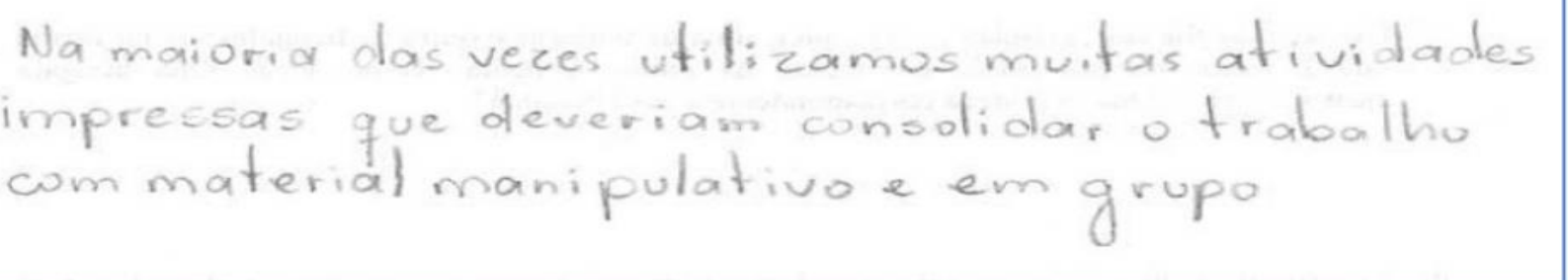


d) Elenque os objetivos em se trabalhar os conceitos de número cardinal e ordinal dentro dessa perspectiva lúdica.

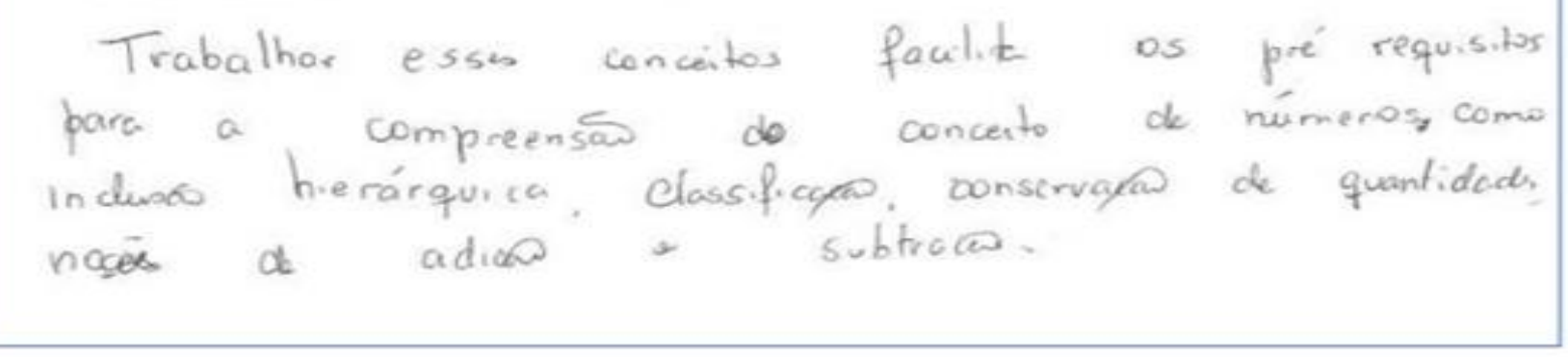

Quanto aos aspectos cardinal e ordinal do número natural, as professoras não ressaltaram nenhuma dessas características. Piaget e Szeminska (1975) abordam em suas experiências tais dimensões desse objeto matemático, fato que leva à conclusão de que, como supracitado no desenvolvimento desta pesquisa, pode haver sim o ensino de um dos aspectos em detrimento do outro, ou, ainda, pode haver uma lacuna ao se ensinar número natural.

Como uma das características da Engenharia Didática de $2^{\mathrm{a}}$ geração, a produção de recurso pedagógico, esse primeiro momento da formação contribuiu para somar recursos às práticas pedagógicas das professoras para o ensino do número natural. Elas salientaram que as experiências Piagetianas desenvolvidas foram relevantes ao somarem às suas metodologias, principalmente pelo fato dessas serem manipulativas, características consideradas mais apropriadas à faixa etária dos(as) alunos(as) dos anos iniciais do ensino fundamental.

d) Considerando sua prática pedagógica usada para ensinar o número natural e seus aspectos cardinal e ordinal, você usaria algumas dessas situaçōes problema para somar ou substituir a sua metodologia?
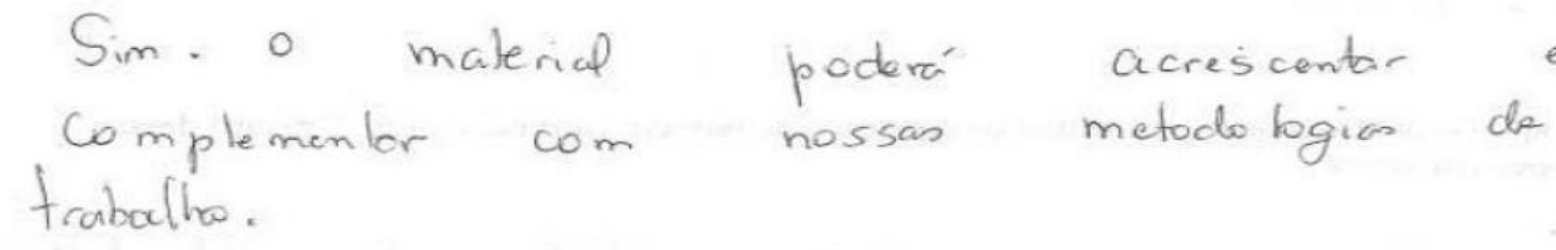

Ainda seguindo as características da metodologia da Engenharia Didática de $2^{\mathrm{a}}$ Geração, quanto à produção de recursos pedagógicos, três observações em sala de aula foram realizadas pelo pesquisador durante o primeiro momento da formação. Diante dessas e segundo as necessidades apresentadas pelas professoras, quanto a abordarem os aspectos cardinal e ordinal, pôde-se constatar que a primeira etapa da formação contribuiu com a prática docente em sala de aula, no que tange a metodologia de ensino, e não 
somente para produção de recursos pedagógicos, pois algumas das professoras desenvolveu com suas respectivas turmas, atividades que lhes foram propostas.

Quanto ao segundo momento da formação, esse teve uma característica mais teórica. O intuito foi analisar com as professoras a teoria que Piaget e Szeminska (1975) usaram para desenvolver suas pesquisas quanto à concepção genética do conceito do número natural. De acordo com a Engenharia Didática de $2^{\mathrm{a}}$ Geração, ela deverá prover, além de recursos pedagógicos, formação de professores.

Com base nessa particularidade, a segunda etapa da formação desenvolvida com as docentes contribuiu para com a forma com que elas conceituam e ensinam o número natural. Tal afirmação se sustenta levando-se em consideração o debate final entre as participantes. Elas salientaram as dificuldades relacionadas ao ensino desse conteúdo, como também enalteceram a oportunidade de terem uma amostra - via formação - de possibilidades que envolvem os aspectos didáticos, pedagógicos e conceituais, em se tratando de abordar de forma complementar os aspectos cardinal e ordinal.

A segunda variável elencada nas análises a priori, ou seja, a promoção e interação entre as professoras sujeitos da pesquisa, foi priorizada nas formações de tal modo que elas pudessem externar suas metodologias desenvolvidas ao ensinarem o número natural. De acordo com o debate entre as participantes, ocorrido no segundo momento da formação, há inúmeros percalços envolvendo o ensino e a aprendizagem do número natural, tais como: grande quantidade de alunos; número de conteúdos e tempo reduzido para apresentá-los; falta de material mais compatível para a faixa etária, ou seja, material concreto; chegada de crianças sem conhecimentos prévios; qualidade da formação na graduação em pedagogia, entre outros. Pode-se constatar, com isso, que as professoras necessitam de um aporte teórico e pedagógico quando se trata de ensino de matemática, em especial o número natural.

\section{CONSIDERAÇÕES FINAIS}

As professoras evidenciaram que se surpreenderam com as experiências piagetianas apresentadas e apontaram o quanto elas podem contribuir no cotidiano escolar, no que se refere ao ensino do número natural. Três professoras desenvolveram com seus (suas) alunos (as) as atividades apresentadas na sequência didática. Elas salientaram o quanto esse recurso metodológico contribuiu para o ensino e, principalmente, para o 
aprendizado, alegando também que, mais capacitadas, elas podem prover um ensino mais qualificado. Ainda por meio das experiências piagetianas, foi possível proporcionar às professoras conhecimentos teóricos e enriquecimento pedagógico direcionados ao número natural e às estratégias pedagógicas para ensiná-lo. O ensino de conceitos matemáticos em geral e do número natural em particular, favorece a aprendizagem, quando embasado em constructos teóricos.

A formação continuada de professores polivalentes que ensinam matemática, tema da investigação base desse artigo, revelou que estratégias metodológicas para o ensino do número natural, fundamentado na teoria Piagetiana, implica na ampliação de possibilidades para o ensino e de desenvolvimento do conhecimento para esses (as) professores (as). O que, em consequência, deve ampliar também o processo de aprendizagem, interesse último de uma formação de professores, pois traz em seu bojo os elementos essenciais da formação do conceito de número em um indivíduo, no caso o(a) aluno(a) dos anos iniciais do ensino fundamental. Já quanto a especificidade da Engenharia Didática de $2^{\mathrm{a}}$ Geração, tendo como sujeito o professor polivalente que ensina matemática, essa é uma possibilidade capaz de nortear processos metodológicos para ensinar número natural, como também, futuras pesquisas.

\section{REFERÊNCIAS}

Almouloud, S. (2007). Fundamentos da Didática da Matemática. Curitiba/PR: Editora UFPR.

Artigue, M. (1988). Ingénierie didactique. In: Equipe DIDIREM, Université Paris (Org.) Recherches en Didactique des Mathématiques. v. 3. La Pensée Sauvage Éditions, p. 281-308.

Artigue, M. (1996). Engenharia Didática. Didáticas das matemáticas (Dir. Jean Brun).

Tradução de Maria José Figueiredo. Lisboa: Instituto Piaget. Horizontes Pedagógicos.

Bellini, M. Burgo, O. \& G. Nogueira, C. M. I. (2007). A Construção do Conceito de Número na Perspectiva Piagetiana: O que pensam os professores. Revista Teoria e Prática da Educação, v.10(3),349 - 361.

Brousseau, G. (2004). Des dispositifs d'apprentissage aux situations didactiques em mathematiques. Conference a L'univesite de Geneve. Recuperado http://guybrousseau.com/wp-content/uploads/2012/12/Des-dispositifs-dapprentissage-auxsituations-didactiques-en-mathématiques.pdf.

Brousseau, G. (2013). Introduction à l'ingénierie didactique. Laboratoire Cultures, Education, Sociétés (LACES), Université Bordeaux. Bordeaux, Fança. Recuperado de http://guy-brousseau.com/2760/introduction-a-l'ingenierie-didactique-2013 
Carvalho, M. (2010). Números. Conceitos e atividades para Educação Infantil e Ensino Fundamental. Petrópolis/RJ. Editora Vozes. 2010

Curi, E. (2014). Formação de Professores Polivalentes: uma análise de conhecimentos para ensinar matemática e de crenças e atitudes que interferem na constituição desses conhecimentos. (Tese de Doutorado em Educação Matemática). Pontifícia Universidade Católica de São Paulo, São Paulo.

Otte, M. F. (2003). Complementarity, Sets and Numbers. Educational Studies in Mathematics. Printed in the Netherlands: Kluwer Acadmic Publishers. v. (53), 203-228. Recuperado de https://link.springer.com/article/10.1023\%2FA\%3A1026001332585

Panizza, M. (2006). Ensinar Matemática na Educação Infantil e nas Séries Iniciais. Análises e Propostas. Porto Alegre/RS: Editora Artmed.

Perrin-glorian, M.J; Mangiante-Orsola, C. (2016). Ingenierie Didactique de Developpement en Geometrie au Cycle 3 dans le Cadre du Lea Valenciennes-Denain. Actes du séminaire national de didactique des mathématiques (version provisoire prépublication). $34 \quad$ - 59. Recuperado de https://ardm.eu/wpcontent/uploads/2017/02/pre actes seminaire ARDM janvier 2016.pdf

Perrin-glorian, M. J; Bellemain, P. M. B. (2016). L'ingenierie Didactique entre Recherche et Ressource pour L'Enseignement et la Formation des Maitres. I Simpósio Latino Americano de Didática da Matemática. Recuperado de http://www.ppgedcmar.ufscar.br/events/10-simposio-latino-americano-de-didatica-da-matematica

Piaget, J. Szeminska, A. (1975). A Gênese do Número na Criança. Tradução: Christiano Monteiro Oiticica. Rio de Janeiro/RJ: Zahar.

\section{NOTAS}

TÍTULO DA OBRA

Uma Formação Continuada, por meio da Engenharia Didática, de Professoras Polivalentes com foco em conhecimentos e práticas pedagógicas referentes ao conceito de número natural.

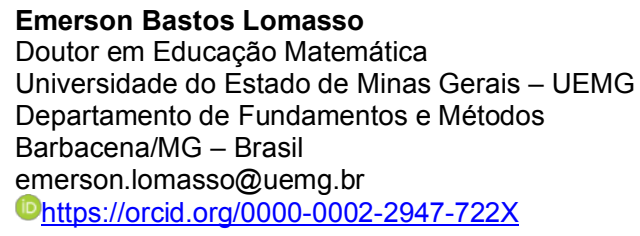

Endereço de correspondência do principal autor

Rua Cachoeira Dourada 130, bairro Paraíso, cep. 30270 060. Belo Horizonte, MG. Brasil.

\section{AGRADECIMENTOS}

Não se aplica.

\section{CONTRIBUIÇÃO DE AUTORIA}

Concepção e elaboração do manuscrito: Lomasso, E. B.

Coleta de dados: Lomasso, E. B.

Análise de dados: Lomasso, E. B.

Discussão dos resultados: Lomasso, E. B. 
Revisão e aprovação: Lomasso, E. B.

\section{CONJUNTO DE DADOS DE PESQUISA}

Todo o conjunto de dados que dá suporte aos resultados deste estudo foi publicado no próprio artigo.

FINANCIAMENTO

Não se aplica.

\section{CONSENTIMENTO DE USO DE IMAGEM}

Não se aplica.

\section{APROVAÇÃO DE COMITÊ DE ÉTICA EM PESQUISA \\ Não se aplica.}

\section{CONFLITO DE INTERESSES}

Não se aplica.

LICENÇA DE USO - uso exclusivo da revista

Os autores cedem à Revemat os direitos exclusivos de primeira publicação, com o trabalho simultaneamente licenciado sob a Licença Creative Commons Attribution (CC BY) 4.0 International. Estra licença permite que terceiros remixem, adaptem e criem a partir do trabalho publicado, atribuindo o devido crédito de autoria e publicação inicial neste periódico. Os autores têm autorização para assumir contratos adicionais separadamente, para distribuição não exclusiva da versão do trabalho publicada neste periódico (ex.: publicar em repositório institucional, em site pessoal, publicar uma tradução, ou como capítulo de livro), com reconhecimento de autoria e publicação inicial neste periódico.

PUBLISHER - uso exclusivo da revista

Universidade Federal de Santa Catarina. Grupo de Pesquisa em Epistemologia e Ensino de Matemática (GPEEM). Publicação no Portal de Periódicos UFSC. As ideias expressadas neste artigo são de responsabilidade de seus autores, não representando, necessariamente, a opinião dos editores ou da universidade.

EDITOR - uso exclusivo da revista

Méricles Thadeu Moretti e Rosilene Beatriz Machado.

HISTÓRICO - uso exclusivo da revista

Recebido em: 21-09-2020 - Aprovado em: 12-11-2020 